\title{
IMPLEMENTASI NILAI KARAKTER DAN MORAL MAHASISWA MELALUI TUTOR SEBAYA KEPADA MAHASISWA BERKEBUTUHAN KHUSUS
}

\author{
Dwi Setianingsih \\ Universitas PGRI Yogyakarta \\ dwisetianingsih@upy.ac.id
}

\begin{abstract}
Abstrak
Penelitian ini bertujuan untuk mengetahui implementasi nilai karakter dan moral mahasiswa melalui tutor sebaya dengan penanaman nilai karakter dan moral mahasiswa melalui tutor sebaya kepada mahasiswa berkebutuhan khusus, mata kuliah Psikologi Anak Berkebutuhan Khusus prodi PLB FKIP UPY. Desain penelitian menggunakan pendekatan kualitatif dan metode yang digunakan adalah studi kasus. Partisipan dalam penelitian ini adalah mahasiswa semester dua mata kuliah Psikologi Anak Berkebutuhan Khusus prodi PLB FKIP UPY. Teknik pengumpulan data menggunakan observasi, wawancara, dokumentasi. Pengujian keabsahan data dengan cara perpanjangan pengamatan dan triangulasi. Teknik pengolahan dan analisis data menggunakan analisis proses siklus yang interaktif yang terdiri dari reduksi data, penyajian data, dan verifikasi data. Hasil penelitian adalah terdapat beberapa nilai karakter dan moral yang diimplementasikan pada mata kuliah Psikologi Anak Berkebutuhan Khusus antara lain: toleransi, kerja keras, semangat kebangsaan, bersahabat/komunikatif, peduli sosial dan tanggung jawab.
\end{abstract}

Kata kunci: Nilai Karakter dan Moral, tutor sebaya, mahasiswa berkebutuhan khusus, Psikologi ABK

\section{PENDAHULUAN}

Pendidikan merupakan hak semua warga negara Indonesia, tidak terkecuali untuk anak berkebutuhan khusus. Berdasarkan Undang-Undang Dasar 1945 Pasal 31 ayat (1) bahwa: "Setiap warga negara berhak mendapat pendidikan" (Undang-Undang Dasar, 1945), maka anak berkebutuhan khusus juga memiliki hak yang sama dalam mendapatkan pendidikan. Selanjutnya masih di pasal yang sama, ayat (3) bahwa " pemerintah mengusahakan dan menyelenggarakan satu sistem pendidikan nasional yang meningkatkan keimanan dan ketakwaan serta akhlak mulia dalam rangka mencerdaskan kehidupan bangsa, yang diatur dengan undang-undang" (Undang-Undang Dasar, 1945).

Undang-Undang Penyandang Disabilitas tahu 2016 menjelaskan secara rinci, hak apa saja yang harus dipenuhi oleh pemerintah dalam rangka kesetaraan dalam pendidikan. kualitas manusia Indonesia yang harus dikembangkan oleh setiap satuan pendidikan. Sebagai wujud implementasi dari Undang-Undang Penyandang Disabilitas, di setiap perguruan tinggi wajib menyelenggarakan pendidikan inklusif. 
Sebagai universitas yang inklusif, menerima mahasiswa berkebutuhan khusus di salah satu program studi adalah suatu keharusan. Tidak terkecuali pada Program Studi Pendidikan Luar Biasa, juga menerima mahasiswa berkebutuhan khusus. Sehingga dalam pelaksanaan pendidikan juga memperhatikan kebutuhan belajar setiap mahasiswa berkebutuhan khusus tersebut. Terdapat 4 mahasiswa berkebutuhan khusus di program studi PLB FKIP UPY, yaitu 1 mahasiswa dengan hambatan penglihatan, serta 3 mahasiswa dengan hambatan pendengaran.

Pada semester gasal, mahasiswa sudah dibekali mata kuliah Ortopedagogik umum, yaitu pengenalan mengenai macam-macam jenis anak berkebutuhan khusus beserta kebutuhan belajarnya. Mata kuliah Psikologi ABK, bertujuan untuk membekali mahasiswa agar memiliki pengetahuan tentang psikologis dari anak berkebutuhan khusus. Mata Kuliah ini meliputi konsep SD Inklusif, identifikasi dan asesmen siswa berkebutuhan khusus, dan penanganan siswa berkebutuhan khusus.

Fakta di lapangan menunjukkan bahwa mahasiswa belum pernah berinteraksi dengan anak berkebutuhan khusus secara intens. Sehingga dalam perkuliahan dapat melatih untuk dapat saling mengenal dan memahami bagaimana psikologi anak berkebutuhan khusus,

supaya

dapat mengimplementasikan nilai karakter dan moral dalam kehidupan sehari-hari. Materi mata kuliah Psikologi Anak Berkebutuhan Khusus sebagai salah satu mata kuliah wajib pada Program Studi Pendidikan Luar Biasa akan menjadi sangat teoritis bagi mahasiswa ketika mahasiswa hanya belajar konsep tentang Anak Berkebutuhan Khusus tanpa disertai upaya nyata menerapkan materi tersebut dalam lingkungan sosial. Lebih lanjut tanpa adanya implikasi materi mata kuliah tersebut, penanaman nilai karakter dan moral mahasiswa untuk peduli membantu layanan dan bimbingan bagi anak berkebutuhan khusus tidak dapat berjalan optimal.

Penerapan tutor sebaya kepada mahasiswa berkebutuhan khusus ini memiliki esensi yang sangat erat kaitanya dengan nilai karakter dan moral. Dalam pendidikan karakter di Indonesia, tercakup 18 pilar/nilai karakter yang perlu dikembangkan dalam penyelenggaraan pendidikan, yakni :

Tabel 1. 18 Nilai Karakter

\begin{tabular}{|l|l|}
\hline Religius & $\begin{array}{l}\text { Semangat } \\
\text { Kebangsaan }\end{array}$ \\
\hline Jujur & Cinta Tanah Air \\
\hline Toleransi & $\begin{array}{l}\text { Menghargai } \\
\text { Prestasi }\end{array}$ \\
\hline Disiplin & $\begin{array}{l}\text { Bersahabat/ } \\
\text { Komunikatif }\end{array}$ \\
\hline Kerja Keras & Cinta Damai \\
\hline Kreatif & Gemar Membaca \\
\hline
\end{tabular}




\begin{tabular}{|l|l|}
\hline Mandiri & $\begin{array}{l}\text { Peduli } \\
\text { Lingkungan }\end{array}$ \\
\hline Demokratis & Peduli Sosial \\
\hline Rasa Ingin Tau & Tanggung Jawab \\
\hline
\end{tabular}

*Pusat Kurikulum Balitbang Diknas (2011)

Terkait dasar, fungsi dan pilar pendidikan karakter pada beberapa paparan tersebut, pendidikan karakter tidak dapat dipisahkan dengan pendidikan inklusi yang sarat dengan keberagaman, terutamapada setting pendidikan. Berdasarkan hal tersebut fokus penelitian ini adalah pendeskripsian secara mendalam pelaksanaan perkuliahan Mata Kuliah Psikologi Anak Berkebutuhan Khusus untuk mengimplementasikan nilai karakter dan moral mahasiswa melalui tutor sebaya kepada mahasiswa berkebutuhan khusus.

\section{METODE}

Desain penelitian yang digunakan dalam penelitian ini adalah pendekatan kualitatif. Peneliti menggunakan pendekatan kualitatif karena penelitian ini merupakan penelitian lapangan untuk mendeskripsikan dan menganalisis fenomena, peristiwa, aktifitas suatu kelompok dalam hal ini adalah pelaksanaan perkuliahan Mata Kuliah Psikologi Anak Berkebutuhan Khusus di Prodi PLB FKIP Universitas PGRI Yogyakarta.

Sejalan dengan tujuan dan rumusan masalah penelitian, penelitian ini menggunakan pendekatan kualitatif dengan menggunakan metode penelitian kualitatif deskriptif dengan desain studi kasus. Langkah-langkah yang dilakukan dalam analisis data yaitu melalui reduksi data, penyajian data atau display data dan penarikan kesimpulan (konklusi) dan verifikasi (Creswell, 2008: 244), dengan partisipan penelitian adalah mahasiswa PLB UPY Semester 2 yang terdaftar pada mata kuliah Psikologi Anak Berkebutuhan Khusus.

\section{HASIL DAN PEMBAHASAN}

\section{Hasil}

Mata kuliah Psikologi Anak Berkebutuhan Khusus merupakan mata kuliah wajib dengan bobot 2 SKS yang harus ditempuh oleh mahasiswa prodi PLB. Materi yang dibahas dalam mata kuliah Psikologi Anak Berkebutuhan Khusus adalah materi yang berhubungan dengan bergabagai jenis kemampuan, hambatan, dan kebutuhan khusus anak-anak yang berbeda dengan anak pada umumnya, bagaimana membantu anak berkebutuhan khusus untuk dapat memperoleh layanan pendidikan bersama anak lain yang tidak berkebutuhan khusus, serta bagaimana anak berkebutuhan khusus ini dapat diterima di masyarakat.

Selain membekali mahasiswa dalam mengenal ragam kebutuhan khusus anak, juga bertujuan agar mahasiswa memiliki karakter terutama kepedulian dengan anak berkebutuhan khusus di lingkungan sekitarnya. Dalam 
mencapai tujuan tersebut, perkuliahan Mata Kuliah Psikologi Anak Berkebutuhan Khusus dilaksanakan dalam 3 setting perkuliahan. Ketiga setting perkuliahan tersebut dipaparkan dalam tabel 2 berikut:

Tabel 2. Setting Perkuliahan Mata Kuliah Psikologi ABK

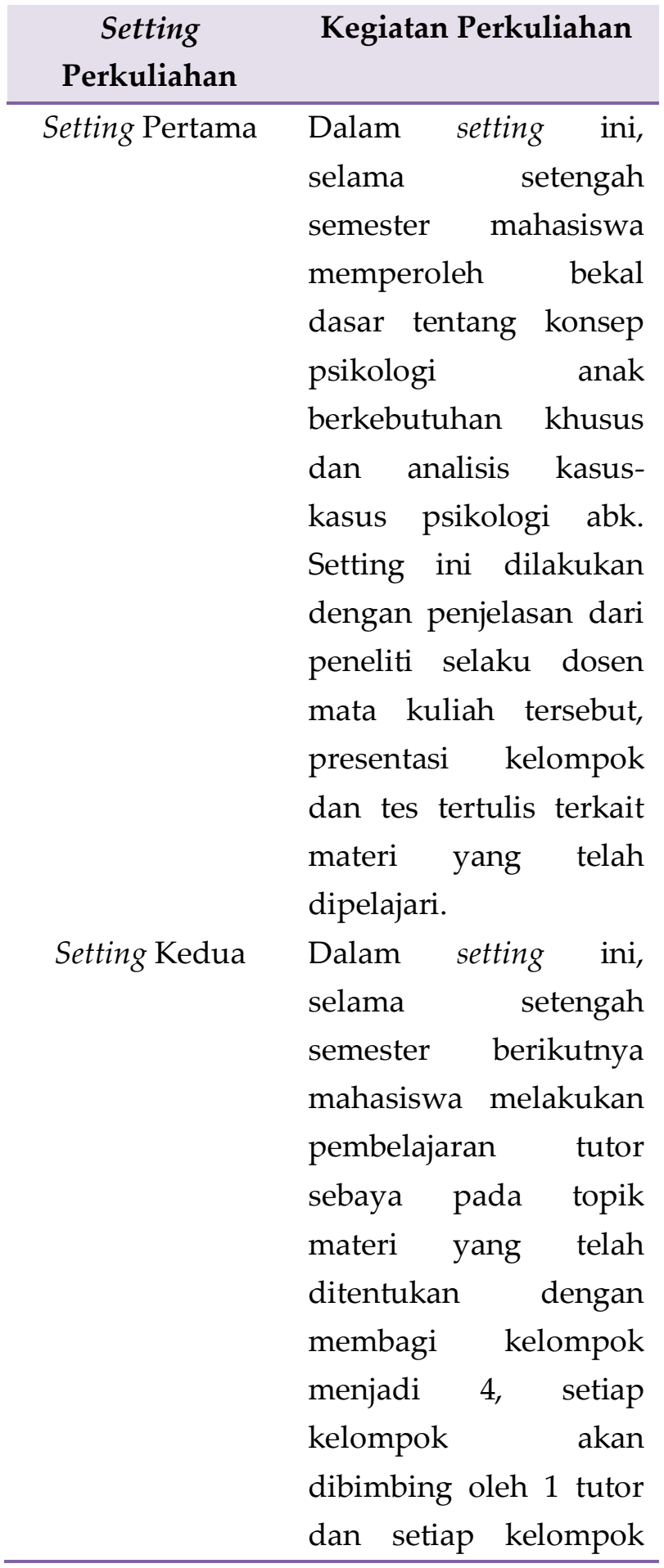

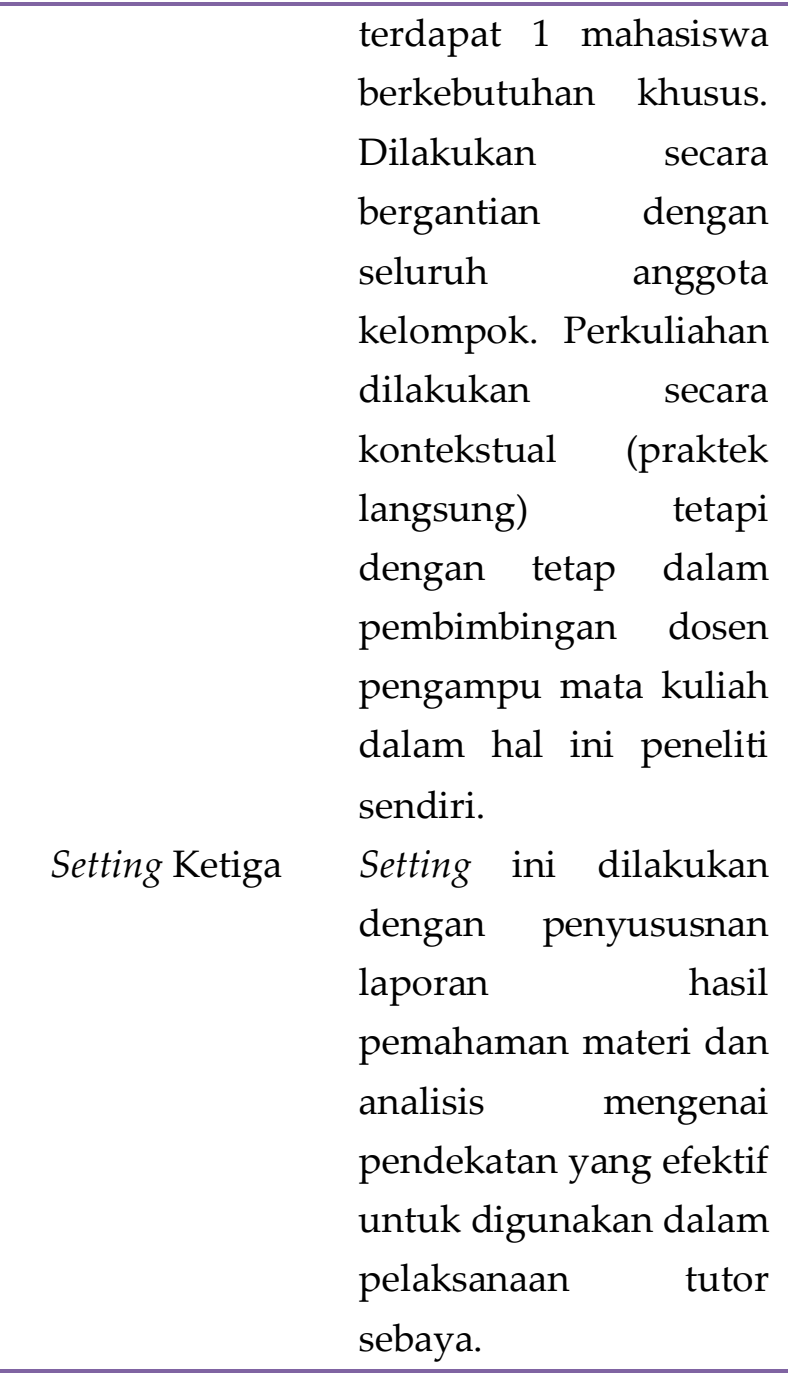

Hasil observasi dalam penelitian ini menunjukkan bahwa setting pertama ditekankan pada memberikan pengetahuan pada mahasiswa terkait psikologi anak berkebutuhan khusus untuk membangun pengetahuan moral mahasiswa utamanya kepedulian terhadap anak berkebutuhan khusus di lingkunganya. Setting kedua dalam perkuliahan lebih ditekankan agar mahasiswa memiliki perasaan moral dengan berinteraksi langsung dalam sebuah setting pendidikan melalui tutor sebaya kepada mahasiswa berkebutuhan khusus. Sedangkan setting terakhir 
menekankan pada kemampuan mahasiswa bertindak berdasarkan pengetahuan dan pengalaman langsung yang telah diperoleh pada setting perkuliahan pertama dan kedua.

Hasil wawancara menunjukkan bahwa dengan praktek langsung berinteraksi dalam setting pendidikan melalui tutor sebaya kepada mahasiswa berkebutuhan khusus baik pada mahasiwa yang memiliki hambatan penglihaan serta mahasiswa dengan hambatan pendengaran, mahasiswa dapat lebih memahami esensi materi perkuliahan melalui sudut pandang mahasiswa berkebutuhan khusus serta berdiskusi sehingga pemahaman yang diperoleh semua mahaiswa kurang lebih sama, serta menerapkan langsung materi yang mereka pelajari. Dengan kefahaman dan pengalaman tersebut mereka merasa memilki tingkat kepedulian yang lebih kepada anak berkebutuhan khusus, toleransi dengan berbagai keberagaman siswa, dan dapat menjalin komunikasi yang lebih intens dengan mahasiswa berkebutuhan khusus.

Berdasarkan studi dokumentasi terkait laporan akhir mahasiswa, mereka telah mampu menunjukkan tindakan moral yang tepat yakni dengan membantu menyusun pendekatan yang disesuaikan dengan kemampuan dan kebutuhan mahasiswa berkebutuhan khusus yang mereka ajari. Hal tersebut menujukkan bahwa mahasiswa memiliki karakter bersemangat dan bertanggung jawab dalam membantu anak berkebutuhan khusus.

\section{Pembahasan}

Hasil penelitian ini menunjukkan bahwa Mata Kuliah Anak Berkebutuhan Khusus dan Pendidikan Inklusi dapat menamankan nilai karakter dan moral mahasiswa ketika tidak berhenti pada penjelasan materi perkuliahan saja, tetapi ada pengalaman langsung dalam membantu anak berkebutuhan khusus dalam memahami suatu materi. Hasil penelitian ini sesuai dengan teori Lickona (2013: 85-100) yang mendeskripsikan masing-masing komponen dalam pembinaan karakter dan dapat diperoleh mahasiswa selama proses perkuliahan Mata Kuliah Psikologi Anak Berkebutuhan Khusus. Komponen-komponen tersebut adalah: a. Pengetahuan Moral (Moral Knowing) Dalam komponen ini terdapat enam aspek sebagai tujuan diajarkanya moral knowing. Enam aspek tersebut meliputi 1) kesadaran moral / moral awareness; 2 ) mengetahui tentang nilai moral/knowing moral values; 3) penentuan perspektif/perspective taking; 4) pemikiran moral/moral reasoning; 5) pengambilan keputusan / decision making; 6) dan pengetahuan pribadi/self knowledge moral feeling.

b.Perasaan Moral(Moral Loving)

Dalam komponen ini terdapat enam aspek dari emosinal yang harus 
dirasakan oleh seseorang untuk melalui interkasi secara langsung menjadi manusia berkarakter yaitu: 1) kepada mahasiswa berkebutuhan hati nurani/conscience; 2) harga diri/ khusus dalam setting pendidikan self esteem; 3) empati/empathy; 4) melalui metode tutor sebaya. Tindakan mencintai hal yang baik/loving the Moral (Moral Action) mahasiswa dapat good; 5) kontrol diri/self control; dan 6) terlatih ketika mereka dibimbing kerendahan diri/huminity.

c. Tindakan Moral (Moral Action)

Tindakan moral merupakan hasil (outcome) dari 2 komponen karakter lainya. Untuk memahami apa yang mendorong individu dalam menyusun laporan terkait solusi yang dapat ditawarkan khususnya dalam kegiatan pembelajaran untuk membantu mahasiswa berkebutuhan khusus yang telah mereka ajari.

Mahasiswa PLB selaku calon guru perbuatan yang baik (act morally) maka harus dilihat tiga aspek lain dari karakter yaitu: 1) kompetensi/ competence; 2) keinginan/will; dan 3) kebiasaan/habbit.

Pengetahuan Moral (Moral Knowing) dapat ditanamkan kepada mahasiswa melalui Mata Kuliah Psikologi Anak Berkebutuhan Khusus melalui penyajian materi secara komprehensif dan mendalam tentang materi yang berhubungan dengan bergabagai jenis kemampuan, hambatan, dan kebutuhan khusus anak-anak yang berbeda dengan anak pada umumnya, bagaimana membantu anak berkebutuhan khusus untuk dapat memperoleh layanan pendidikan bersama anak lain yang tidak berkebutuhan khusus, serta bagaimana anak berkebutuhan khusus ini dapat diterima di masyarakat. Perasaan Moral (Moral Feeling) dapat ditanamkan kepada mahasiswa melalui Mata Kuliah Psikologi Anak Berkebutuhan Khusus SLB sangat memerlukan penanaman nilai karakter dan moral sebelum menjadi seorang guru. Lickona dalam Erawati, dkk (2016: 4) mengungkapkan bahwa guru harus mampu mendidik dan menanamkan nilai moral. Jika guru bermaksud menanamkan nilai moral, maka yang harus dilakukan: Pertama, guru menjadi seorang penyayang yang efektif. Kedua, guru menjadi seorang model, yaitu orang-orang yang beretika yang menunjukkan rasa hormat dan tanggung jawab yang tinggi baik di dalam maupun di luar kelas. Ketiga, guru menjadi mentor yang beretika.

Berdasarkan 18 nilai karakter yang telahdirumuskan dalamPusat Kurikulum, Balitbang Diknas yakni (1) Religius; (2) Jujur; (3) Toleransi; (4) Disiplin; (5) Kerja Keras; (6) Kreatif; (7) Mandiri; (8) Demokratis; (9) Rasa Ingin Tau; (10) Semangat Kebangsaan; (11) Cinta Tanah Air; (12) Menghargai Prestasi; (13) Bersahabat/Komunikatif; (14) Cinta Damai; (15) Gemar Membaca; 
(16) Peduli Lingkungan; (17) Peduli Sosial; dan (18) Tanggung Jawab, setidaknya terdapat 6 karakter yang dapat ditanamkan pada mahasiswa melalui Mata Kuliah Psikologi Anak Berkebutuhan Khusus yakni karakter toleransi, kerja keras, semangat kebangsaan, bersahabat/komunikatif, peduli sosial dan tanggung jawab.

Karakter yang dimiliki mahasiswa sebagai calon guru tersebut kelak juga dapat membantu mereka dalam membantu siswa berkebutuhan khusus di kelas inklusi. Riasti (2015:5) menjelaskan bahwa dalam kelas inklusi guru perlu menentukan nilai-nilai karakter yang menjadi prioritas untuk ditanamkan pada siswa. Guru menekankan pada nilai karakter toleransi, kerja keras dan peduli. Guru menjelaskan nilai-nilai karakter tersebut secara terintegrasi dalam pembelajaran. Guru menjelaskan dengan memberikan contoh kontekstual kepada siswa. Guru berupaya untuk menggali materi pembelajaran dalam menanamkan konsep mengenai karakter menghargai dan membantu. Guru berupaya memberikan contoh tindakan yang sesuai dan tidak sesuai dengan nilainilai karakter.

\section{Karakter toleransi dapat} ditanamkan dengan mahasiswa melihat secara langsung kemampuan dan hambatan yang dialami siswa berkebutuhan khusus sehingga tidak menyamaratakan kemampuan bahkan membanding-bandingkan anak berkebutuhan khusus dengan anak lain yang tidak berkebutuhan khusus. Karakter semangat kebangsaan terwujud dengan kefahaman mahasiswa bahkan anak berkebutuhan khusus juga merupakan bagian dari bangsa Indonesia yang berhak memperoleh pendidikan bersama anak lain yang tidak berkebutuhan khusus. Penanaman nilai karakter bersahabat/komunikatif pada mahasiswa dapat terwujud melalui interaksi langsung mahasiswa dengan anak berkebutuhan khusus, guru kelas, guru pendamping khusus, serta orang tua anak berkebutuhan khusus. Karakter peduli sosial dan tanggung jawab dapat ditanamkan kepada mahasiswa sebagai calon guru melalui dengan melaporkan dan menindak lanjuti hasil studi lapangan mereka melalui kegiatan menyusun program pembelajaran yang dapat membantu anak berkebutuhan khusus.

\section{SIMPULAN}

Mata Kuliah Psikologi Anak Berkebutuhan Khusus selain membekali mahasiswa dalam mengenal ragam kebutuhan khusus anak, juga bertujuan agar mahasiswa memiliki karakter terutama kepedulian dengan anak berkebutuhan khusus di lingkungan sekitarnya. Dalam mencapai tujuan tersebut, perkuliahan Mata Kuliah Psikologi Anak Berkebutuhan Khusus 
dapat dilaksanakan dalam berbagai setting perkuliahan.

Melalui 3 setting kegiatan perkuliahan (pemaparan materi di kelas, tutor sebaya, dan penyusunan laporan terkait tindak lanjut tutor sebaya), terdapat 6 karakter yang dapat ditanamkan pada mahasiswa melalui Mata Kuliah Psikologi Anak Berkebutuhan Khusus yakni karakter toleransi, kerja keras, semangat kebangsaan, bersahabat/komunikatif, peduli sosial dan tanggung jawab.

\section{Rekomendasi}

Berdasarkan hasil temuan dan pembahasan penelitian ini, peneliti merumuskan beberapa rekomendasi sebagai berikut: Mata Kuliah Psikologi Anak Berkebutuhan Khusus dapat diselenggarakan dengan berbagai variasi model dan setting perkuliahan dengan tetap memperhatikan ketercapaian kompetensi mata kuliah dan penanaman karakter bagi mahasiswa. Selain itu peneliti juga mengharapkan adanya kerjasama dari segenap stake holder pendidikan bagi anak berkebutuhan khusus, untuk membantu mahasiswa dalam melaksanakan kegiatan observasi pembelajaran di sekolah.

\section{DAFTAR PUSTAKA}

\section{Buku}

Creswell, J. W. 2008. Educational Research - Planning, Conducting, And Evaluating Quantitative And
Qualitative Research. Third Edition. New Jersey: Pearson Education, Inc.

Lickona, Thomas. 2013. Mendidik untuk Membentuk Karakter Bagaimana Sekolah dapat Mengajarkan Sikap Hormat, dan Tanggung Jawab. Jakarta: PT. Bumi Aksara.

Pusat Kurikulum dan Perbukuan. 2011. Panduan Pelaksanaan Pendidikan Karakter. Jakarta: Pusat Kurikulum dan Perbukuan.

\section{Artikel/Jurnal}

Erawati, Eka Leli. dkk. 2016. Pendidikan

Karakter Bangsa Pada Anak Berkebutuhan Khusus dalam Pendidikan Inklusi. Jurnal Studi Sosial Vol 4 No 1.

Riasti, Erlis. 2015. Implementasi Pendidikan Karakter Pada Kelas Inklusi di SD Negeri Widoro Kecamatan Pengasih Kabupaten Kulon Progo.Jurnal Pendidikan Guru Sekolah Dasar Edisi 9 Tahun ke IV Mei 2015.

\section{Dokumen Resmi}

Undang-Undang Dasar 1945.

Undang-Undang Republik Indonesia No. 20 tahun 2003 Tentang Sistem Pendidikan Nasional. Jakarta: Depdiknas

Undang-Undang Republik Indonesia No. 8 tahun 2016 Tentang Penyandang Disabilitas. Jakarta: Depdiknas. 